\begin{tabular}{|c|c|c|}
\hline$\exists$ & $\begin{array}{c}\text { International Journal of Current Research } \\
\text { and Academic Review }\end{array}$ & 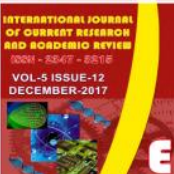 \\
\hline $\begin{array}{l}\text { EXCELLENT } \\
\text { PUBLISHERS }\end{array}$ & $\begin{array}{c}\text { ISSN: 2347-3215 (Online) } \\
\text { Journal homepage: heltp:///www.ijcrar.com } \\
\end{array}$ & \\
\hline
\end{tabular}

doi: https://doi.org/10.20546/ijcrar.2017.512.003

\title{
Synthesis and Optical Characterization of Silver Nanoparticles (Ag-NPs) Thin Films (TFs) Prepared by Silar Technique
}

\author{
D. O. Samson ${ }^{1 *}$, T. O. Adeeko ${ }^{1}$ and E. K. Makama ${ }^{2}$ \\ ${ }^{1}$ Department of Physics, University of Abuja, P.M.B 117, Abuja, Nigeria \\ ${ }^{2}$ Department of Physics, University of Jos, P.M.B. 2084, Nigeria
}

*Corresponding author

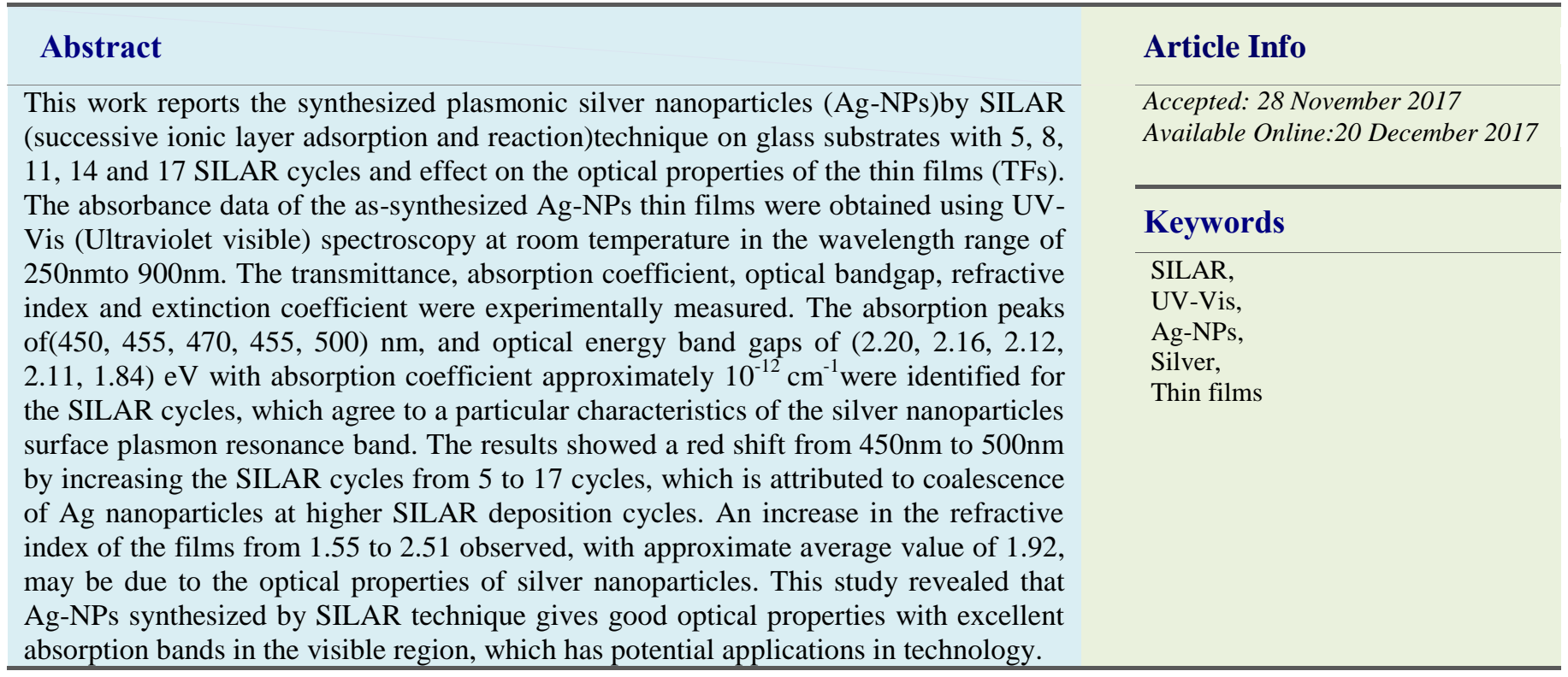

\section{Introduction}

Recently, the preparation of silver nanoparticles (Ag-NPs or nanosilver) materials has attracted increasing interest from fundamental point of view due to their unique optical (Kreibig and Vollmer, 1995), electronic, and catalytic properties (Schmid, 1994), which are different from their macro-scaled counterparts and hence lead to novel applications in sensor, catalysts, nanoelectronic devices, biochemical tagging reagents, optical switches, and so on (Greenwood and Earnshaw, 1997; Templeton, 2000). The growing interest in the use of Ag-NPs most especially in surface science has however generated a lot of concerns about the techniques of synthesis and characterization.

To this day a lot of research has been focused on silver nanoparticles because of their important scientific and technological applications in colour filters (Quinten, 2001, Biswas et al., 2004), optical switching (Stegeman and Wright, 1999), optical sensors (Biswas, 2006), and especially in surface enhanced Raman scattering (Khan, et al., 2011). Such properties and applications strongly depend on the morphology, crystal structure and 
dimensions of silver nanostructures. One of the most interesting features of $\mathrm{Ag}$ nanostructures is the presence of enhanced light scattering, strong absorption in the visible region, and large local field enhancement near the nanostructure surface at the resonant condition known as the Localized Surface Plasmon Resonance (LSPR), which is as a result of coherent oscillation of the conduction electrons upon exposure to light of specific wavelength (González et al., 2014).

The geometrical and spectral characteristics of silver nanoparticle, such as size, shape, inter-particle spacing and the environment provide important control on linear and nonlinear optical properties (Bruzzone et al., 2005). The excitation of the plasmon enhances the electromagnetic field in the surrounding environment and produce measurable changes in nanoparticle that response in the optical field. Several techniques has been employed in preparing silver nanostructures such as polyol process, seed mediated growth, photochemical, sonochemical, electrochemical, dc magnetron sputtering (Li et al., 2009), RF magnetron sputtering (Elanchezhiyan et al., 2009), spray pyrolysis (Reddy and Reddy, 2005), pulse electro-deposition (Cheng et al., 2007), chemical bath deposition (CBD) (Kathalinham et al., 2010; Budhiraja, 2013), vacuum evaporation, SILAR (Ying et al., 2017, Rohom and Sartale, 2011), laser ablation, etc.

Among all of this methods, SILAR is the inexpensive, simplest, possible homogeneous deposition on large and complicated area of substrates, less temperature, easy to handle and low time consuming technique compared to the others (Salunkhe et al., 2009; Su et al., 2012; Mukherjee and Mitra, 2015). SILAR offers a great opportunity and a good numbers of advantages: SILAR does not require high quality target or substrates nor does it require vacuum at any stage, easily controlled rate of the film or nanoparticle deposition and the thickness by changing the deposition cycles, production of films or nanoparticle can be made possible at room temperature on less robust materials. It does not cause local overheating that can bedetrimental for materialsto bedeposited and there are almost no limitations on substratematerial, dimensionsor its surfaceprofile (Pathan and Lokhande, 2004; Mitzi, 2009). In addition, SILAR can be used for large area thin film deposition and the thickness can be controlled by the number of dipping. Our main focus is to synthesize plasmonic silver nanoparticles (Ag-NPs) by SILAR techniques with the view to study the effects of the SILAR cycles on the optical properties of the thin films.

\section{Experimental}

\section{Materials and Methods}

All reagents and solvents used for this study were of analytical grade and do not require any further purification. Silver nitrate $\left(\mathrm{AgNO}_{3}: 99 \%\right)(\mathrm{BDH})$, stannous chloride $\left(\mathrm{SnCl}_{2} \cdot 2 \mathrm{H}_{2} \mathrm{O} ; 97 \%\right) \quad(\mathrm{BDH})$ was obtained from Quality Control and Testing Laboratories Ltd. Ammonium solution $\left(\mathrm{NH}_{3} \mathrm{OH}\right)$ (ca. $33 \%$ wt $\mathrm{NH}$ ), hydrochloric acid $(\mathrm{HCl})(36 \%)$ were purchased from Katchey Company Ltd,diammine silver complex,Sodalime-silica glass, Sodium lauryl sulfate (sodium dodecyl sulfate), Methanoland distilled water.

\section{Sample preparation by SILAR technique}

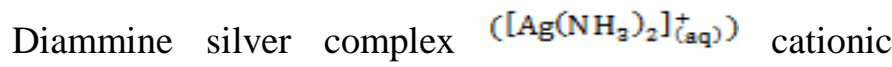
precursor and stannous chloride are used as anionic reducing solution at room temperature. Soda-lime-silica glass was used as substrates in the deposition of Ag-NPs thin films (TFs). The glass substrates were cleaned with soap (Sodium lauryl sulfate), rinsed with methanol and dried by heating in air at $75^{\circ} \mathrm{C}$. Double distilled water was used as solvent and both solutions were magnetically stirred for ensuring homogeneous mixing. The diammine silver complexsolution was prepared by adding $0.35 \mathrm{~g}$ of $\mathrm{AgNO}_{\mathrm{a}}(\mathrm{BDH})$ in $200 \mathrm{ml}$ of distilled water, then add drop wise ammonia solution $\left(\mathrm{NH}_{2} \mathrm{OH}\right)$ until the precipitate of $\mathrm{AgOH}$ was transformed into soluble $\left(\mathrm{CAg}^{\left.\left(\mathrm{NH}_{2}\right)_{2}\right]_{(\mathrm{aq}))}^{+}}\right.$. Nitric acid and ammonia solution were used to adjust the $\mathrm{pH}$ values of silver nitrate and diammine silver complex solution until colourless solution was observed and $0.01 \mathrm{M}$ of cationic precursor concentration was obtained. We then prepared the anionic (reducing agent) solution by adding $2 \mathrm{ml}$ of

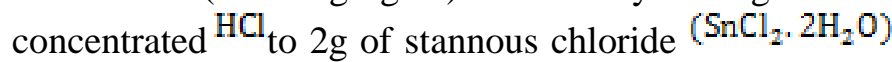
$(\mathrm{BDH})$ in $640 \mathrm{ml}$ of distilled water to obtain $0.2 \mathrm{M}$ concentration. Four beakers containing cationic precursor, distilled water, anionic (reducing agent) solution and distilled water were placed in successive arrangement for the deposition of the films, the prepared glass substrate was immersed in the diammine silver complex $\left(\left[\mathrm{Ag}\left(\mathrm{NH}_{3}\right)_{2}\right]_{(a q)}^{+}\right)$solution for 10 seconds (adsorption), then rinsed with distilled water for about 5 seconds, the glass substrate was then transferred to the stannous chloride solution for 10seconds (reduction reaction), films turns brownish due to the reduction from $\mathrm{Ag}^{+}$to $\mathrm{Ag}$ and finally rinsed with distilled water for 5 
seconds to remove the excess, unreacted species, reaction by-product from the diffusion layer and to get the homogeneity. This completes one SILAR cycle, this process was repeated until a required number of cycles were obtained. The samples were prepared for $5,8,11$, 14 and 17 SILAR cycles and annealed at $100^{\circ} \mathrm{C}$ for 30 minutes and allowed to cool at room temperature before characterisation. The chemical reaction mechanism for the formation of Ag-NPs is given as follow:

\section{Cationic precursor (Adsorption step)}

Diammine silver complex cationic precursor is obtained

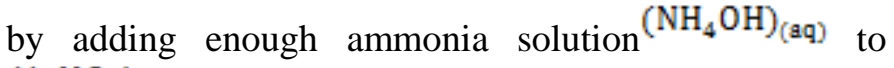
$\left(\mathrm{AgNO}_{\mathrm{a}}\right)_{\mathrm{laq}}$. Brownish precipitate appears when a small amount of ammonia solution is added as a result of the formation of silver (I) oxide ${ }^{\left(\mathrm{Ag}_{2} \mathrm{O}\right)(s)}$ :

$$
2 \mathrm{AgNO}_{3(a q)}+2 \mathrm{NH}_{4} \mathrm{OH}_{(a q)} \rightarrow \mathrm{Ag}_{2} \mathrm{O}_{(s)}+2 \mathrm{NH}_{4} \mathrm{NO}_{3(a q)}+\mathrm{H}_{2} \mathrm{O}_{(l)}
$$

The precipitate ${ }^{\left(\mathrm{Ag}_{2} \mathrm{O}\right)(\mathrm{s})}$ dissolves in excess ammonia solution to form colourless diammine silver complex ion:

$$
\mathrm{Ag}_{2} \mathrm{O}_{(s)}+4 \mathrm{NH}_{3}+\mathrm{H}_{2} \mathrm{O}_{(l)} \rightarrow 2\left[\mathrm{Ag}\left(\mathrm{NH}_{3}\right)_{2}\right]_{(a q)}^{+}+2 \mathrm{OH}_{(a q)}^{-}
$$

The ionic equation of the complex ion is given as:

$$
\left[\mathrm{Ag}\left(\mathrm{NH}_{3}\right)_{2}\right]_{(a q)}^{+} \rightarrow \mathrm{Ag}_{(a q)}^{+}+2 \mathrm{NH}_{3(l)}
$$

\section{Anionic precursor (reaction step)}

Tin (II) chloride dissolves in less than its own mass of water to form insoluble tin hydroxy chloride specie in a reversible hydrolysisas shown in equation (4), and a clear solution of ${ }^{\mathrm{SnCl}_{2(\mathrm{aq})}}$ requires addition of excess ${ }^{\mathrm{HCl}}$ is illustrated in equation (5).

$$
\begin{aligned}
& \mathrm{SnCl}_{2}+\mathrm{H}_{2} \mathrm{O} \leftrightarrow \mathrm{Sn}(\mathrm{OH}) \mathrm{Cl}_{(s)}+\mathrm{HCl}_{(a q)} \\
& \mathrm{Sn}(\mathrm{OH}) \mathrm{Cl}_{(s)}+\mathrm{HCl}_{(a q)} \rightarrow \mathrm{SnCl}_{2(a q)}+2 \mathrm{H}_{2} \mathrm{O}
\end{aligned}
$$

Where;

$$
\mathrm{SnCl} l_{2(a q)} \rightarrow \mathrm{Sn}^{2+}+2 \mathrm{Cl}^{-}
$$

$\mathrm{Ag}^{+}$is therefore reduced to $\mathrm{Ag}$ when the films were immersed in the anionic solution containing $S n_{(a q)}^{2+}$ as thus:

$$
A g^{+}+\operatorname{Sn}_{(a q)}^{2+} \rightarrow 2 A g_{(s)}+S n^{4+}
$$

\section{Optical properties characterisation}

The absorption properties of the synthesized materials were analysed by using Axiom Medicals UV 752 spectrophotometer at room temperature in the wavelength range of $250 \mathrm{~nm}$ to $900 \mathrm{~nm}$. The expression for the transmittance $(\mathrm{T})$ of the Ag-NPs thin films were obtained by using equation (8):

$$
\begin{aligned}
& A=2-\log _{10} \% T \\
& R=1-T-A
\end{aligned}
$$

We then obtained an expression for the absorption coefficient ${ }^{\left({ }^{\infty}\right)}$ of Ag-NPs thin films for this study by using the following relation:

$\propto=\frac{2.303 A}{d}$

Where; $\mathrm{d}$ is the film thickness, $\mathrm{A}$ is absorbance $\mathrm{R}$ is reflectance of the film. The optical absorption coefficient ${ }^{(\alpha)}$ dependent on the energy of incident photon and determined by equation (11).

$$
\propto h v \approx B\left(h v-E_{g}\right)^{n / 2}
$$

Where; $\mathrm{B}$ is the constant of proportionality, ${ }^{\propto}$ is absorption coefficient, $\mathrm{h}$ is plank's constant, and $v$ is frequency of the incident photons, ${ }^{h v}$ is energy of the absorbance, $\mathrm{E}_{\mathrm{g}}$ is optical band gap energy (separation between the valence and conduction bands) and the component ${ }^{n}$ depends on the transition. The value of $n=\frac{1}{2}, \frac{a}{2}, 1,2$ or 3 , which depends on the nature of the electronic transition of the gap materials. For the direct gap materials $^{n=1}$, the above relation becomes:

$$
(\propto h v)^{2}=h v-E_{g}
$$


The value of optical band gap can be obtained by plotting a linear graph of $(\propto h v)^{2}$ against photon energy ${ }^{(h v)}$ known as Tauc's plot and have been drawn for thin films deposited with different concentration (see figure 4), this means that the mode of transition in these films is of a direct nature. We obtain expression for the refractive index (n) of the films from the transmission spectra using the relation of equation (13) and considered highest transmission $\left(\mathrm{T}_{\max }\right)$ at wavelength $740 \mathrm{~nm}$ and lowest transmission $\left(\mathrm{T}_{\min }\right)$ at wavelength $380 \mathrm{~nm}$. Then used (equation 13) to derive an expression for the extinction coefficient $(\mathrm{k})$, which describes the attenuation of light in a medium. The greater attenuation of light in a thin film and higher probability of raising the electron transfer across the mobility gap with the photon energy represent the higher values of $k$.

$n=\sqrt{\left(\frac{n_{a}^{2}+n_{g}^{2}}{2}+2 n_{a} n_{g} T_{o}\right)+\left\{\left(\frac{n_{a}^{2}+n_{g}^{2}}{2}+2 n_{a} n_{g} T_{o}\right)^{2}-n_{a}^{2} n_{g}^{2}\right\}^{1 / 2}}$

$T_{0}=\left(\frac{T_{\max }-T_{\min }}{T_{\max } \times T_{\min }}\right)$

$k=\frac{\propto \lambda}{4 \pi}$

Where ${ }^{\mathrm{n}_{\mathrm{a}}}$ and ${ }^{\mathrm{n}_{\mathrm{g}}}$ are the refractive index of air and glass, and $\lambda$ is the wavelength.

\section{Results and Discussion}

\section{Optical Absorption}

UV-Visabsorption spectra have been proved to be useful in indicating the formation of silver particles. The UVVis absorption spectra of as-synthesised silver nanoparticles (Ag-NPs) on glass substrate for the SILAR cycles are shown in figures 1 and 2 . It is clear from the absorption spectra that the maximum absorbance wavelengths $\left(\lambda_{\max }\right)$ are $450 \mathrm{~nm}, 455 \mathrm{~nm}, 470 \mathrm{~nm}, 455 \mathrm{~nm}$, and $500 \mathrm{~nm}$ for $5,8,11,14$ and 17 SILAR cycles respectively.

The above figure demonstrate absorption red shift peak at about $450 \mathrm{~nm}$ to $500 \mathrm{~nm}$ by increasing the SILAR cycles from 5 to 17 cycles. An obvious characteristic plasmon maximum at this wavelength became evident, indicating the formation of silver nanoparticle. The intensity of the absorption peak increased with time and reflected increased formation of silver particles.

This is due to the increasing in size of the nanoparticles by increasing the SILAR cycles as a result of coalescence of $\mathrm{Ag}$ nanoparticles at higher SILAR deposition cycles (Zong et al., 2014; Isah et al., 2016; Gharibshahi et al., 2017). Similarly, the main absorption peaks observed at $450 \mathrm{~nm}, 455 \mathrm{~nm}, 470 \mathrm{~nm}, 455 \mathrm{~nm}$, and $500 \mathrm{~nm}$ for $5,8,11,14$ and 17 SILAR cycles are proportionate to a peculiar characteristics of the silver nanoparticles surface plasmon resonance band (Zong et al., 2014; Thiwawong et al., 2013). This shows that main absorption peaks were slightly red shifted when the SILAR cycle increased. This result agrees well with the Mie theory for the surface plasmon peak of nanoparticles in UV-visible absorption spectra (Thiwawong et al., 2013; Mie, 1098; Petit, 1993; Mafune et al., 2000).

The optical properties of the silver nanoparticle (AgNPs) are owing to the interaction between incoming light and free conduction electrons. When the wavelength of the incident light matches with the oscillating frequency of the conduction electron, a surface plasmon resonance (SPR) occurs, which causes the absorption and scattering intensities of silver nanoparticles to be much higher than identically sized non-plasmonic nanoparticles and gives rise to the absorption band in the visible region. This surface plasmon resonance peak depends on the particle size, shape, surface charge, separation between the particle and the nature of the environment. The surface structure of the nanoparticles determines the charge of the nanoparticles (Thamilselvi and Radha, 2017).

\section{Transmittance}

The UV-Vis transmission spectra of as-synthesised silver nanoparticles on glass substrate is shown in figure 3 . This indicated that all the films exhibit pronounced surface plasmon absorption especially the films with higher SILAR cycles.

The transmission spectra in figure 3 exhibit minimum within the range $335 \mathrm{~nm}$ to655nm. The transmission peaks slightly shifted towards the higher wavelengths as the number of SILAR cycles increased due to the increased nanoparticles size. 
Fig.1 Super-imposed UV-Vis spectra of Ag nanoparticles at the various SILAR cycles

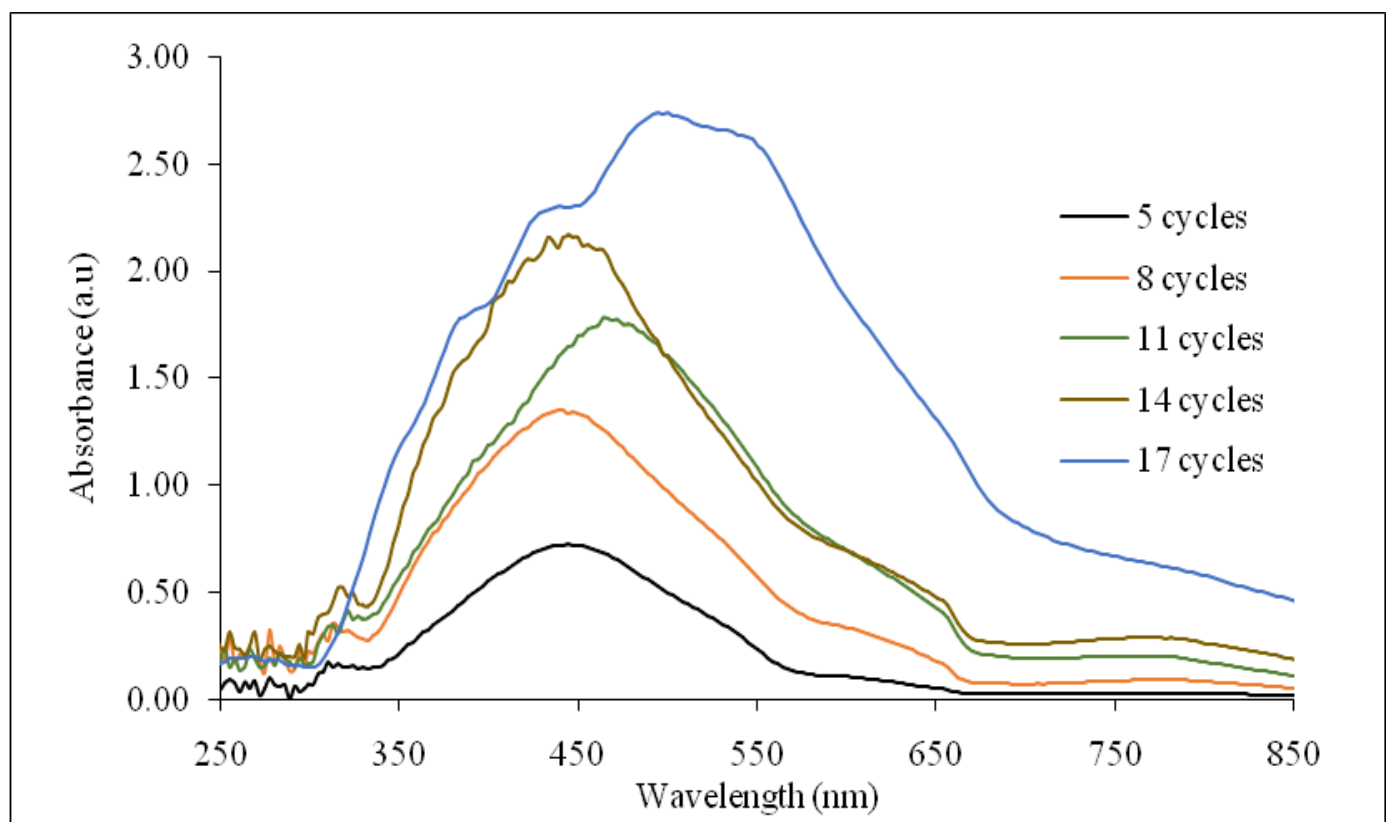

Fig.2 UV-visible absorption spectra of Ag-NPs synthesized at different SILAR cycles
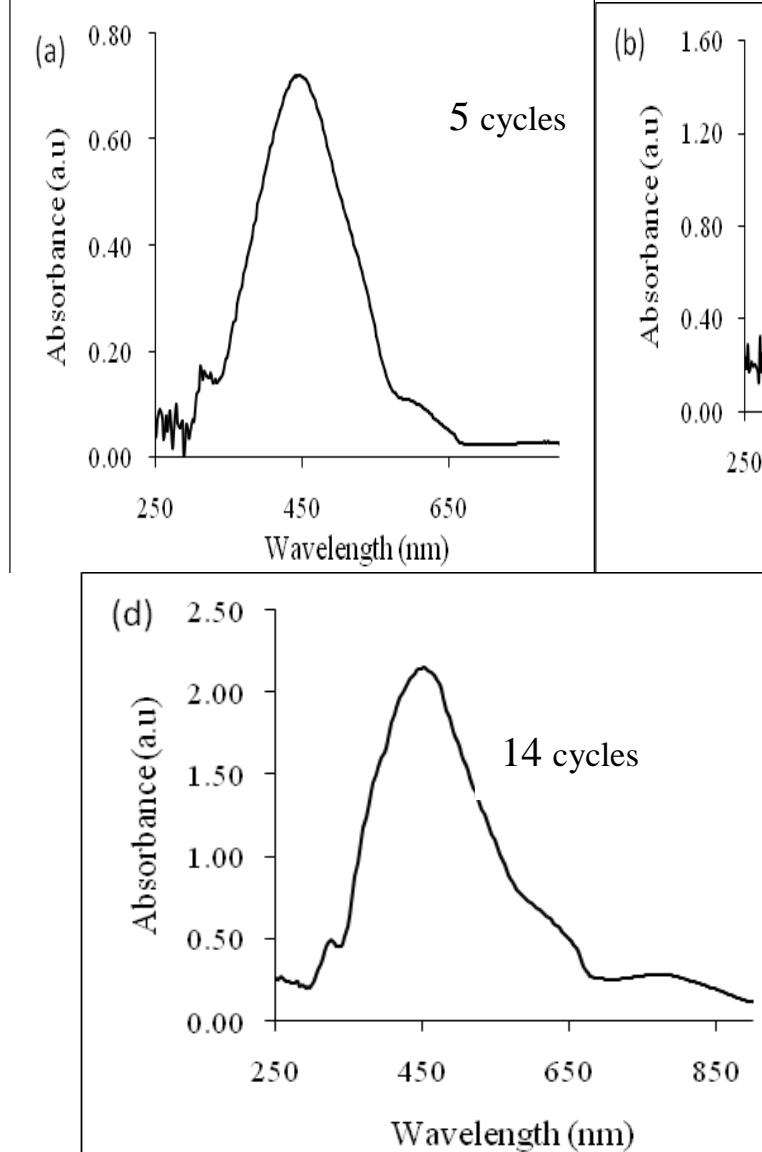
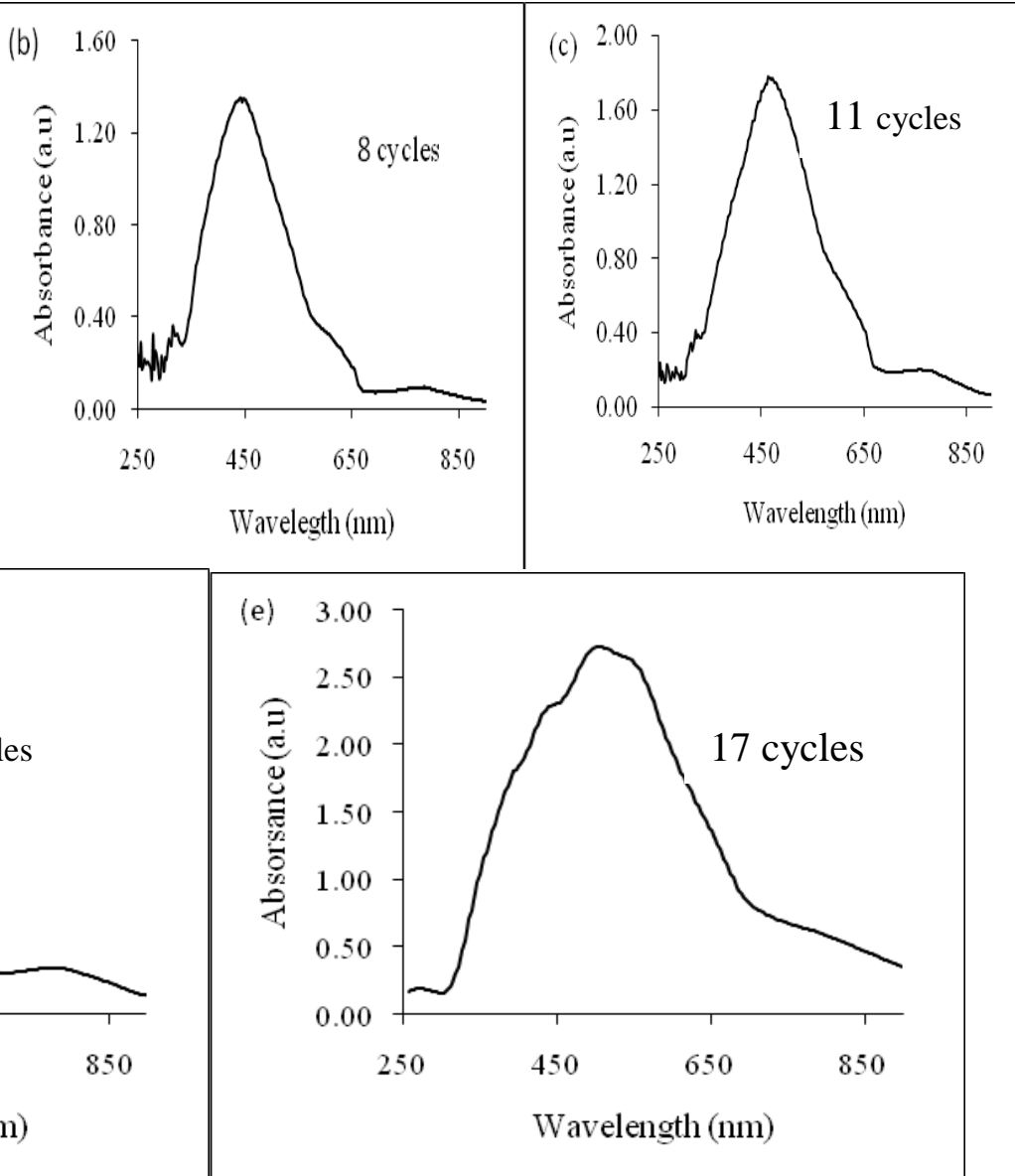
Fig.3 Transmission spectra of silver nanoparticles synthesised at different SILAR cycles

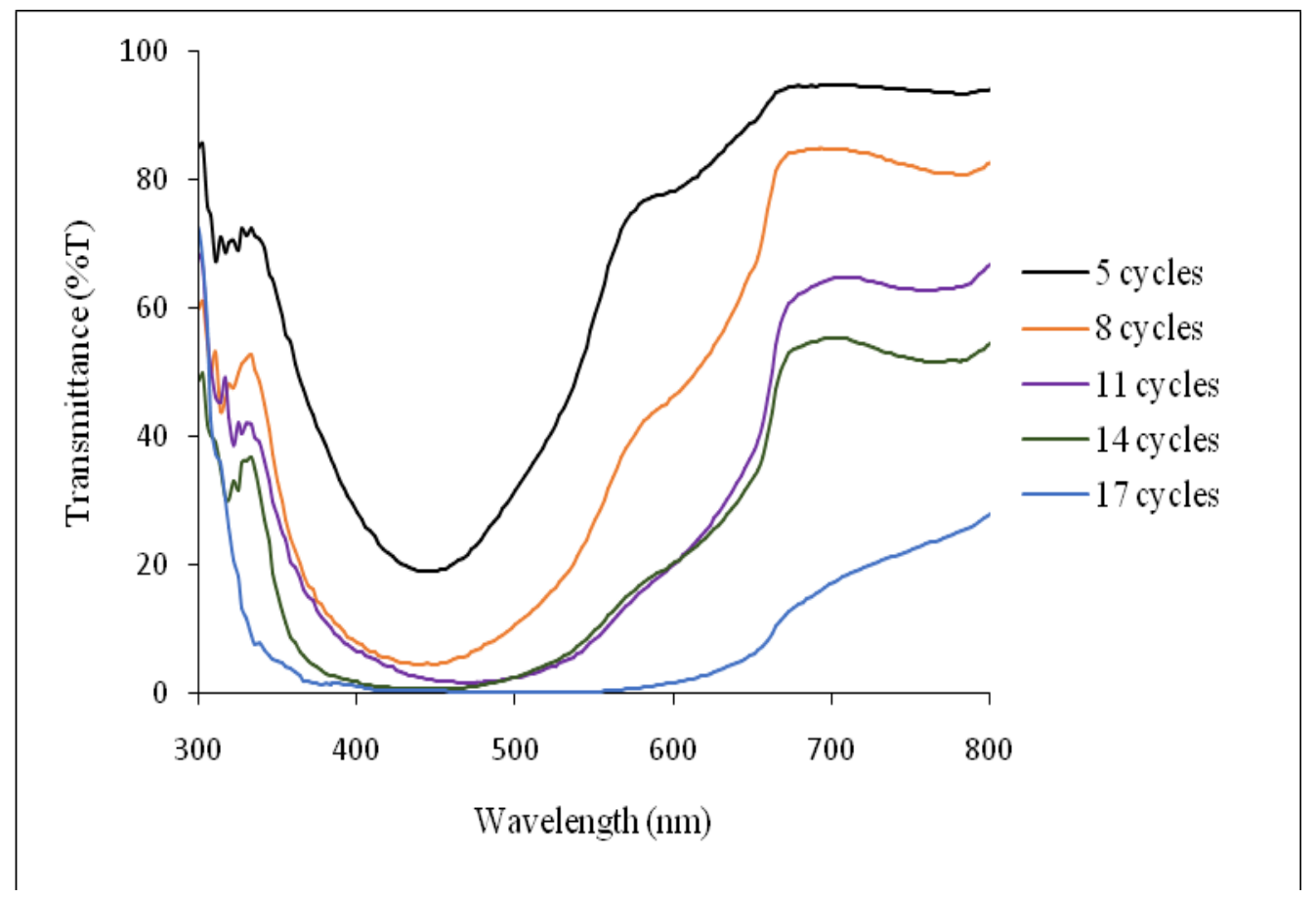

Fig.4 Optical energy band gap for Ag-NPs at different SILAR cycles
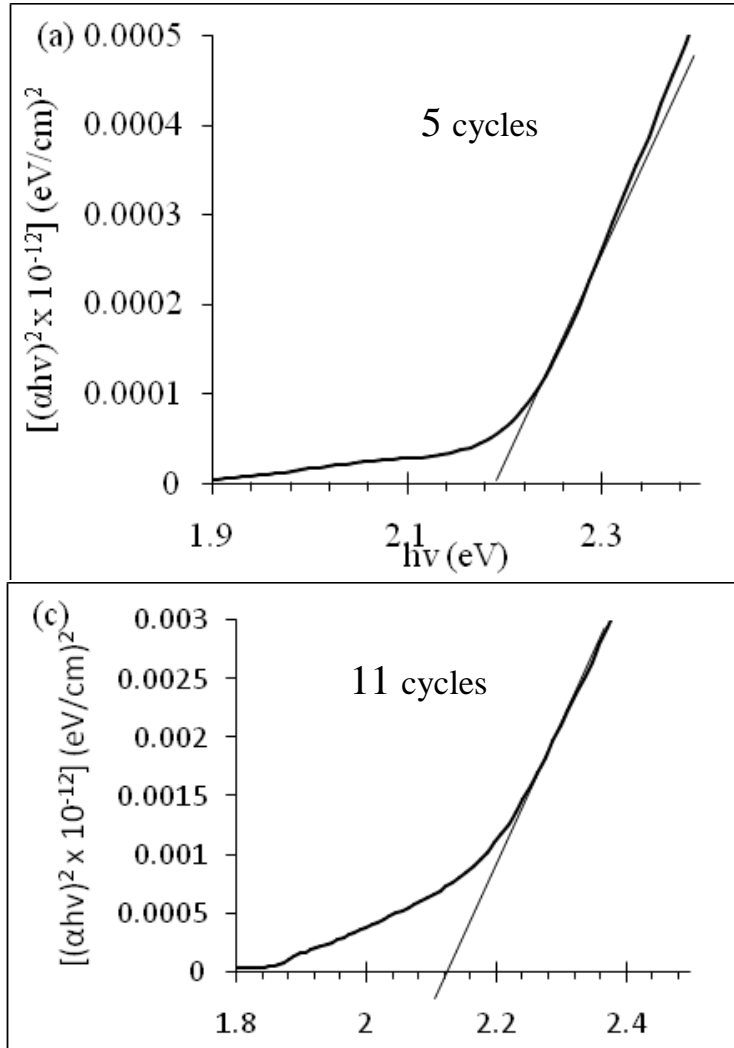

$\mathrm{hv}(\mathrm{eV})$

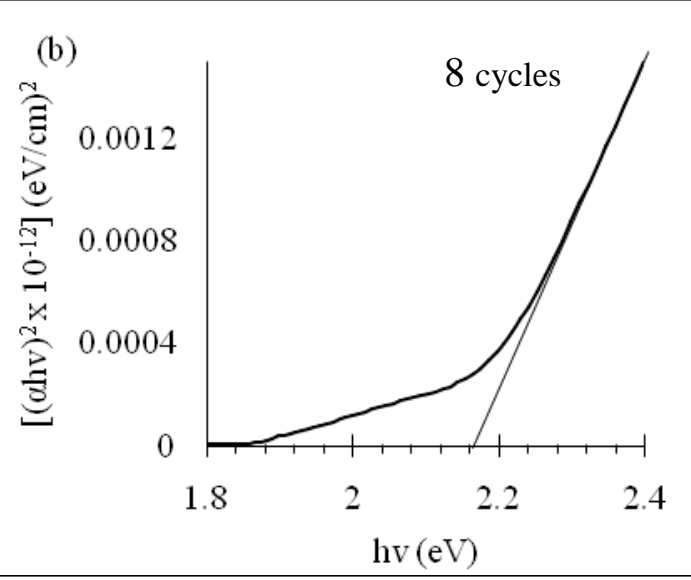

(d)

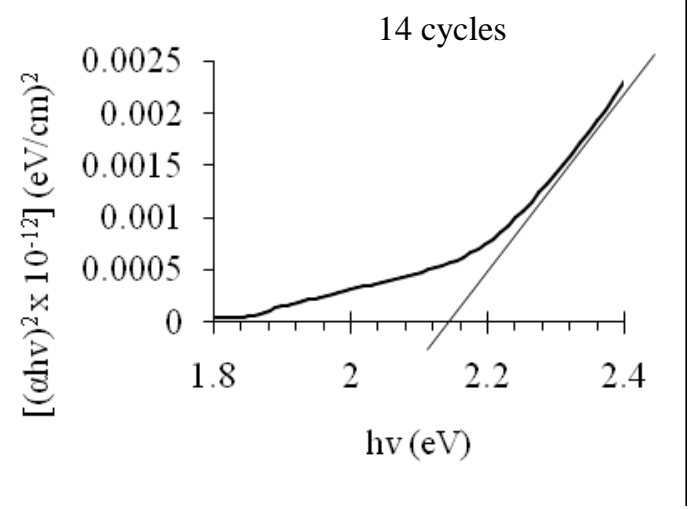




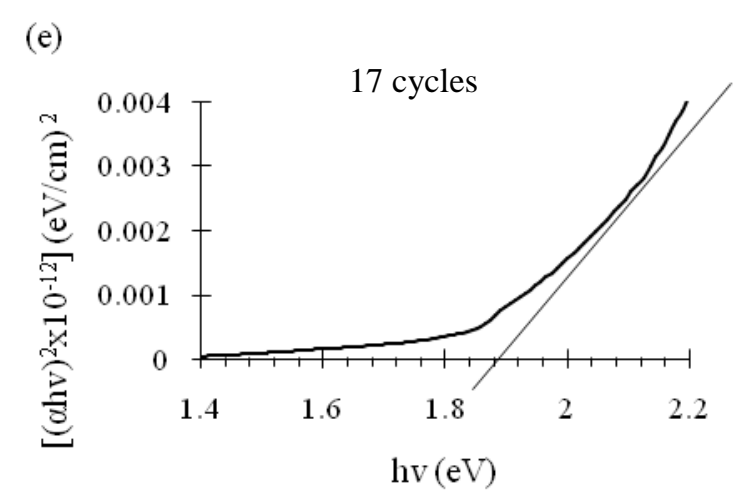

Fig.5 Extinction spectra of Ag-NPs at different SILAR cycles

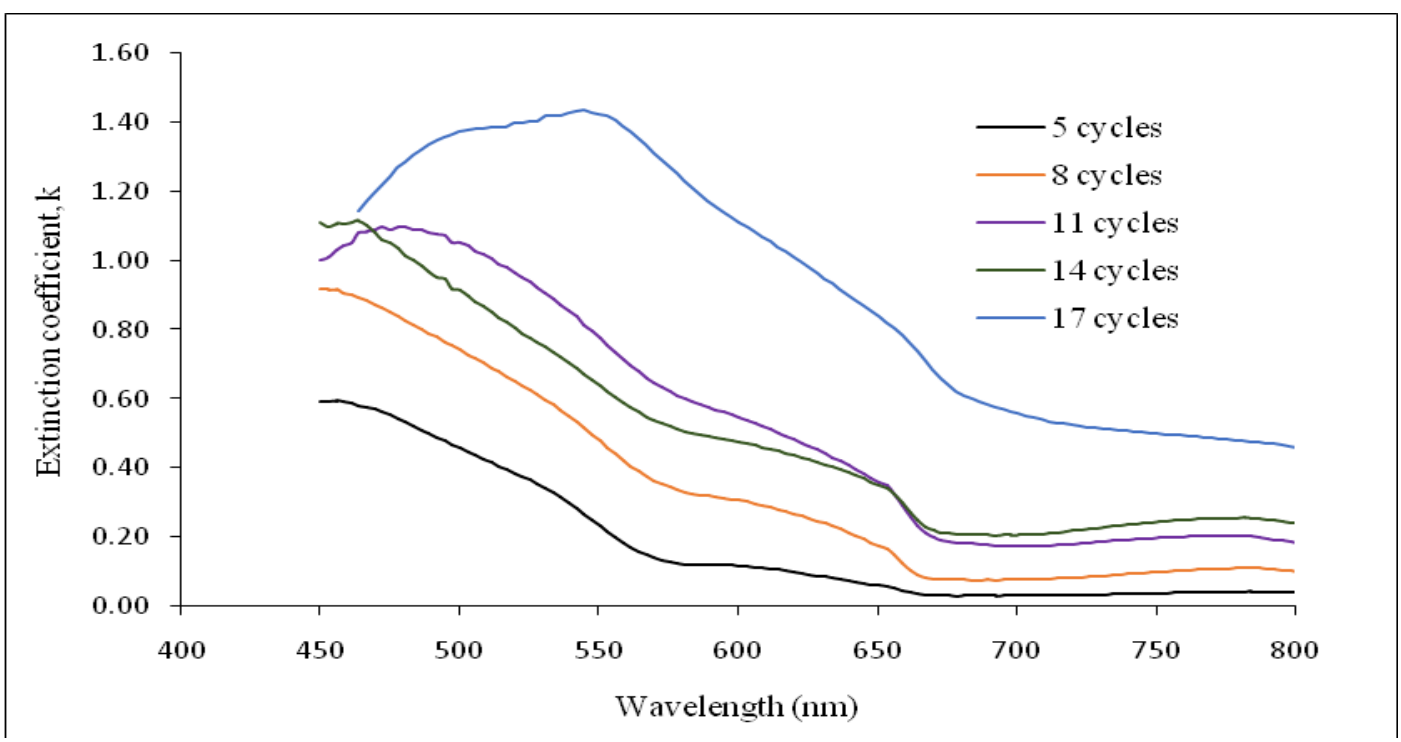

Fig.6 Variation of refractive indices of Ag-NPs with SILAR cycles

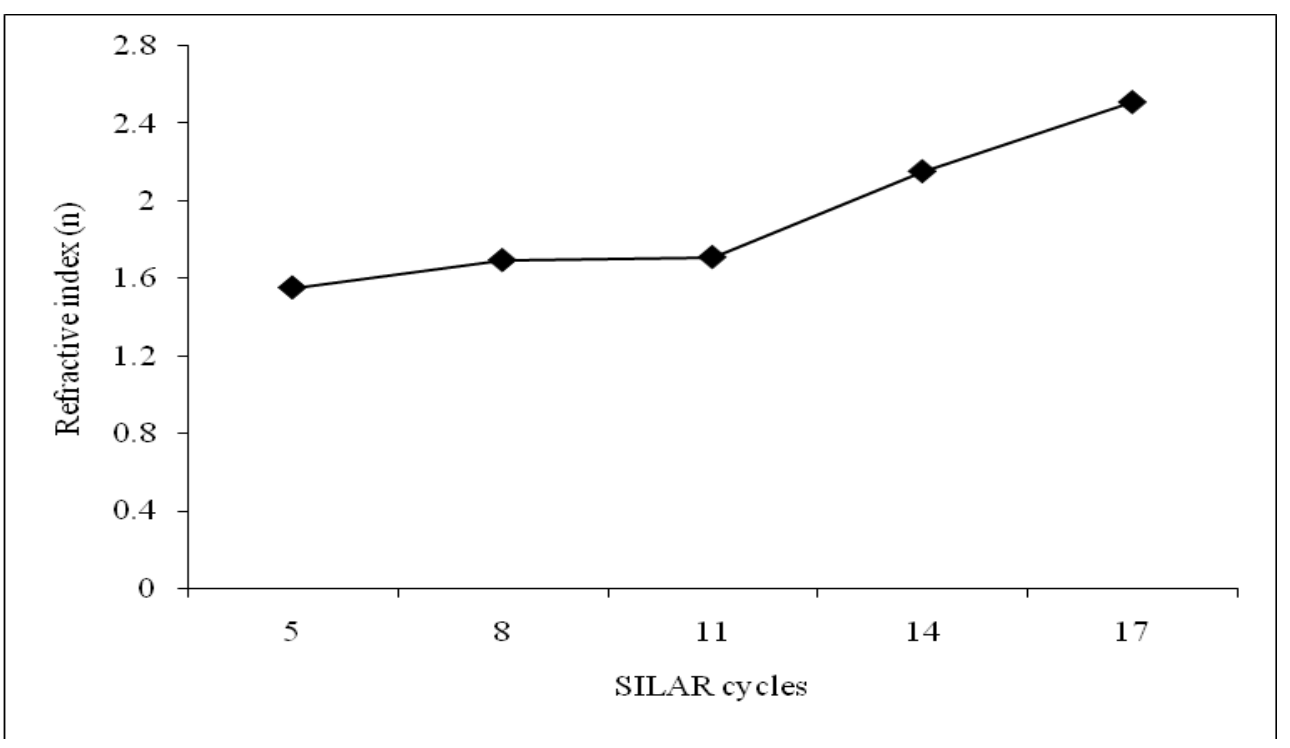


Table.1 Refractive indices of Ag-NPs films at different SILAR cycles

\begin{tabular}{ccc}
\hline Sample & Number of SILAR cycles & Refractive Index (n) \\
\hline AgNPs05 & 5 & 1.55 \\
AgNPs08 & 8 & 1.69 \\
AgNPs11 & 11 & 1.71 \\
AgNPs14 & 14 & 2.15 \\
AgNPs17 & 17 & 2.51 \\
\hline
\end{tabular}

The formation of nanoparticles impedes the propagating surface plasmon polaritons (SPPs) and enhances that of the localised surface plasmon resonance (LSPRs) (Koleva et al., 2012).

\section{Optical BandGap}

We determined the optical bandgap of the silver nanoparticles on glass substrate by using classical Tuac relation (Tauc, 1974) as shown in figure 4 for allowed direct transition of Ag-NPs at different SILAR cycles.

The intersecting point of the extrapolated line at the photon energy (hv) axis indicates the values of direct optical band gap energy, which is uniform with the previous studies (Ying et al., 2017; Ho, 2017). The thin films (TFs) exhibit different optical band gaps energy of $2.20 \mathrm{eV}, 2.16 \mathrm{eV}, 2.12 \mathrm{eV}, 2.11 \mathrm{eV}$ and $1.84 \mathrm{eV}$ with absorption coefficient approximately $10^{-12} \mathrm{~cm}^{-1}$ for 5,8 , 11,14 , and 17 SILAR cycles. It is obvious from figure 4 that by increasing the SILAR cycles, band gaps energy decreases. Such diversity can be assigned to lattice's defects due to the Burstein-Moses effect in the band gap energy (Cristaldi, et al., 2014).

This observation may also be attributed to decrease in reduction of free electrons as a result of increase in localised surface plasmon resonance, scattering effect and quantum confinement effect arising from lowering of particle size. Thus, compositional stoichiometry may also contribute to enhanced band gap.

\section{Extinction Coefficient}

The extinction coefficient of light is the net effect of scattering, absorption, and describes the effect of the interaction between radiation and the matter upon which it impinges (Paramelle et al., 2014). It revealed that extinction coefficient increases with the increase in the SILAR cycles of silver nanoparticles which may be attributed to the contribution of the scattering effects (see figure 5).

\section{Refractive Index}

The summary of the refractive indices of the films are presented in Table 1 and the variation with the SILAR cycles is illustrated in figure 6 .

A linear relationship between the refractive indices (approximate average value of 1.92) Ag-NPs thin films (TFs) and the SILAR deposition cycles was established as shown in figure6. As the SILAR deposition cycles is increased the refractive index also increased which illustrated that the optical properties of silver nanoparticles change when particles aggregate and the conduction electrons near each particle surface become delocalized and are shared amongst neighbouring particles. When this occurs, the surface plasmon resonance shifts to lower energies, causing the absorption and scattering peaks to red shift and longer wavelengths.

It was revealed in this study that the absorption peaks of $450 \mathrm{~nm}, 455 \mathrm{~nm}, 470 \mathrm{~nm}, 455 \mathrm{~nm}$, and $500 \mathrm{~nm}$ were identified for the samples with $5,8,11,14$ and 17 SILAR cycles and at the same time these peaks are proportionate to a peculiar features of the silver nanoparticles surface plasmon resonance band which agrees well with the Mie theory for the surface plasmon peak of nanoparticles in UV-visible absorption spectra. The absorption red shift peak observed from $450 \mathrm{~nm}$ to $500 \mathrm{~nm}$ is due to coalescence of $\mathrm{Ag}$ nanoparticles at higher SILAR deposition cycles. The transmission spectra of the films exhibit minimum within the range $335 \mathrm{~nm}$ to $655 \mathrm{~nm}$, transmission peaks slightly shifted towards the higher wavelengths as the number of SILAR cycles increased. The thin films (TFs) were highly absorbing and the average evaluated optical energy band gaps was approximately $2.09 \mathrm{eV}$. The optical energy band gaps of the thin films (TFs) decreased as the SILAR cycles increased; this observation is attributed to decrease in reduction of free electrons as a result of increase in localised surface plasmon resonance (LSPR) and scattering effects. There is an increase in the 
refractive index of the films from 1.55 to 2.51 with approximate average value of 1.92 , which is explained by the optical properties of silver nanoparticles. Hence, the results obtained from this work shown a good agreement with the data reported in the literature indicating that the synthesis of Ag-NPs by SILAR method can be reliably utilised for the preparation of the Ag-NPs.

\section{Acknowledgements}

The authors gratefully acknowledged the financial support of this work from University of Abuja, AbujaNigeria.

\section{References}

Biswas, A., H. Eilers,F. Hidden, O.C. Aktas, C.V. Kiran 2006. Large broadband visibleto infrared plasmonic absorption from $\mathrm{Ag}$ nanoparticles with a fractalstructure embedded in a Teflon AF (R) matrix. Applied Physics Letters, 88, pp. 13103-13107.

Biswas, A., O.C.Aktas,U. Schurmann, U. Saeed, V. Zaporojtchenko, F. Faupel, T. Strunskus 2004. Tunable multiple plasmon resonance wavelengths responsefrom multi-component polymer-metal nanocomposite systems. Applied Physics Letters, 84, pp. 2655-2659.

Bruzzone, S., M. Malvaldi, G. Arrighini, C. Guiditti 2005. Theoritical study of electromagnetic scattering by metal nanoparticles. Journal of Physical Chemistry B, 109, pp. 3807-3812.

Budhiraja, N., A. Sharma, S. Dahiya, R. Parmar, V. Vidyadharan 2013. Synthesis and optical characteristics of silver nanoparticles on different substrates. International Letters of Chemistry, Physics and Astronomy, ISSN: 2299-3843, 19, pp. 8088,http://doi:10.18052/www.scipress.com/ILCPA.19.8 0

Cheng, S., Y. Chen, Y. He, G. Chen 2007. The structure and properties of $\mathrm{SnS}$ thin films prepared by pulse electro-deposition. Materials Letter, 61, pp. 14081412, www.sciencedirect.com. Accessed 19 July 2016.

Cristaldi, D.A., S. Millesi, I. Crupi, G. Impellizzeri, F. Priolo, R.M.J. Jacobs, R.G. Egdell, A. Gulino 2014. Structural, electronic, and electrical properties of an undoped n-Type $\mathrm{CdO}$ thin film with high electron concentration, Journal of Physical Chemistry, 118 (27), pp. 15019-15026. http://doi:10.1021/jp5040085.

Elanchezhiyan, J., K.P. Bhuvana, N. Gopalakrishnan, B.C. Shin, W.J. Lee, T. Bala-subramanian 2009. Investigations of the properties of $\mathrm{Zn} 1-\mathrm{xCrxO}$ thin films grown by RF magnetron sputtering. Journal of
Alloys and Compounds. 478, pp. 45-48, www.elsevier.com/locate/jallcom.Accessed 5 April 2017.

Gharibshahi, L., E. Saion, E. Gharibshahi, A.H. Shaari, K.A. Matori 2017. Structural and Optical Properties of Ag Nanoparticles Synthesized by Thermal Treatment Method. Materials, 10 (402), pp. 1-13. http://doi:10.3390/ma10040402.

González, A.L., C. Noguez, J. Beránek, A.S. Barnard, 2014. Size, Shape, Stability, and Color of Plasmonic Silver Nanoparticles. Jornal of Physical Chemistry, C, 118, pp. 9128-9136. Retrieved from http://dx.doi.org/10.1021/jp5018168.

Greenwood, N.N., and A. Earnshaw, Chemistry of Elements, 2nd edn. (Butterworth-Heinemann: Oxford, 1997).

Ho, S.M., 2017. Synthesis and Characterization of $\mathrm{Ag}_{2} \mathrm{~S}$ Nano Crystalline Thin Films: A Review. Global Science Chronicle, An open access journal. 1 (1), pp. 1-6, http://doi:10.0000/GSC.1000102. Accessed 28 November 2017.

Isah, K.U., B.J. Jolayemi, U. Ahmadu, M.I. Kimpa, N. Alu, 2016. Plasmonic effect of silver nanoparticles intercalated into mesoporous betalain-sensitized-TiO2 film electrodes on photovoltaic performance of dyesensitized solar cells. Material Renewable and Sustainable Energy, 5 (10), pp. 1-9. http://doi:10.1007/s40243-016-0075-z.

Kathalinham, A., N. Ambika, M.R. Kim, J. Elanchezhiyan, Y.S. Chae, J.K. Rhee 2010. Chemical bathe deposition and characterization of nanocrystalline $\mathrm{ZnO}$ thin films. Material Science-Poland, 28 (2), pp. 513-522, https://www.researchgate.net/publication/230777305. Accessed 25 January 2017.

Khan, M.A., S. Kumar, M. Ahamed, S.A. Alrokayan, M.S. AlSalhi 2011. Structural and thermal studies of silvernanoparticles and electrical transport study oftheir thin films. Nanoscale Research Letters, 6 (434), pp. 1-8. http://doi:10.1186/1556-276X-6-434.

Koleva, M.E., A.O. Dikovska, N.N. Nedyalkov, P.A. Atanasov, I.A. Bliznakova 2012. Enhancement of $\mathrm{ZnO}$ photoluminescence by laser nanostructuring of $\mathrm{Ag}$ underlayer. Applied Surface Science, 258, pp. 91819185.

Kreibig, U., and M. Vollmer, Optical Properties of Metal Clusters. (Springer-Verlag: Berlin, 1995).

Li, X., H. Li, Z. Wang, H. Xia, Z. Xiong, J. Wang, B. Yang 2009. Effect of substrate temperature on the structural and optical properties of $\mathrm{ZnO}$ and $\mathrm{Al}$-doped $\mathrm{ZnO}$ thin films prepared by dc magnetron sputtering. Optics Communications, 282, pp. 247-252, www.elsevier.com/locate/optcom.Accessed 16 July 2016. 
Mafune, F., J. Kohno, Y. Takeda, T. Kondow, H. Sawabe 2000. Structure and stability of silver nanoparticles in aqueous solutionproduced by laser ablation. Journal of Physical Chemistry B, 104 (35), pp. 8333-8337.

Mie, G., 1908. Articles on the optical characteristics of turbid tubes, especially colloidal metal solutions. Annals of Physics, 25, pp. 377-445. Accessed 20 September 2017.

Mitzi, D.B., 2009. Solution Processing of Inorganic Materials. (Hoboken, New Jersey: John Wiley and Sons, Inc., 2009).

Mukherjee, A., and P. Mitra 2015. Structural and optical characteristics of $\mathrm{SnS}$ thin film prepared by SILAR. Materials Science-Poland, 33 (4), pp. 847-851, http://doi:10.1515/msp-2015-

0118,http://www.materialsscience.pwr.wroc.pl.Access ed 13 November 2017.

Paramelle, D., A. Sadovoy, S. Gorelik, P. Free, F. Hobley, D.G. Fernig 2014. Rapid method to estimate the concentration ofcitrate capped silver nanoparticles from UVvisiblelight spectra. Analyst, 139 (1-3), pp. 4855-4861.

http://doi:10.1039/C4AN00978A. Accessed 21 December 2016.

Pathan, H.M., and C.D. Lokhande 2004. Deposition of metal chalcogenide thin films by successive ionic layer adsorption and reaction (SILAR) method. Bulletin of Materials Science, 27 (2), pp. 85-111.

Petit, C., P. Lixon, M. Pileni 1993. In situ synthesis of silver nanoclusterin AOT reverse micelles. Journal of Physical Chemistry, 97 (49), pp. 12974-12983.

Quinten, M., 2001. The color of finely dispersed nanoparticle. Applied Physics B: Lasers Optics, 73, 317-34.

Reddy, N.K., and K.T.R. Reddy 2005. SnS films for photovoltaic applications: Physical investigations on sprayed $\mathrm{Sn}_{\mathrm{x}} \mathrm{S}_{\mathrm{y}}$ films. Physica B: Condensed Matter 368 (1), pp. 25-31, www.sciencedirect.com.Accessed 30 September 2017.

Rohom, A.B., and S.D. Sartale 2011. Deposition and characterization of nanocrystalline silver thim films by using SILAR method. American Institute of Physics Conference Proceedings, 1349, 397, http://dx.doi.org/10.1063/1.3605902.
Salunkhe, R.R., D.S. Dhawale, T.P. Gujar, C.D. Lokhande 2009. Structural, electrical and optical studies of SILAR deposition cadmium oxide thin films: annealing effect. Materials Research Bulletin, 44, pp. 364-368, www.elsevier.com/locate/matresbu.Accessed 8 October 2017.

Schmid, G., Clusters and Colloidal. From Theory to Application. (VCH: Weinheim, 1994).

Stegeman, G.I., and E.M. Wright 1999. All-optical waveguide switching. Optics and Quantum electrodynamics, 22, pp. 95.

Su, Z., K. Sun, Z. Han, F. Lu, Y. Lai, J. Li, Y. Liu 2012. Fabrication of ternary $\mathrm{Cu}-\mathrm{Sn}-\mathrm{S}$ sulfides by a modified successive ionic layer adsorption and reaction (SILAR) method. Journal of Materials Chemistry Issue $22 . \quad$ pp. 16346-16352. http://doi:10.1039/C2JM31669B.

Tauc, J., In Amorphous and Liquid Semiconductor. (Pleum Press, London and New York, 1974. pp. 159.

Templeton, A.C., M.P. Wuelfing, R.W. Murray 2000. Monolayer-protected cluster molecules. Acc. Chem. Res. 33 (1), pp. 27-36.

Thamilselvi, V., and K.V. Radha 2017. A review on the diverse application of silver nanoparticle. IOSR Journal of Pharmacy, 7 (1), pp. 21-27.

Thiwawong, T., K. Onlaor, B. Tunhoo 2013. A Humidity Sensor Based on Silver Nanoparticles Thin Film Prepared by Electrostatic Spray Deposition Process. Advances in Materials Science and Engineering, 640428, pp. 1-7. http://doi:10.1155/2013/640428.

Ying, W., C. Jianyu, J. Liangxing, L. Fangyang, L. Yanqing, L. Jie 2017. Characterization of Bi2S3 thin films synthesized by an improved successive ionic layer adsorption and reaction (SILAR) method. Materials Letters 209, pp. 479-482, www.elsevier.com/locate/mlblue. Accessed 9 November 2017.

Zong, R., X. Wang, S. Shi, Y. Zhu 2014. Kinetically controlled seed-mediated growthof narrow dispersed silver nanoparticles up to120 nm: secondary nucleation, size focusing, and Ostwald ripening. Physical Chemistry Chemical Physics, 16, pp. 42364241. http://doi:10.1039/c3cp54846e.

\section{How to cite this article:}

Samson D. O., T. O. Adeeko and Makama E. K. 2017. Synthesis and Optical Characterization of Silver Nanoparticles (Ag-NPs) Thin Films (TFs) Prepared by Silar Technique. Int.J.Curr.Res.Aca.Rev. 5(12), 15-24. doi: https://doi.org/10.20546/ijcrar.2017.512.003 